\title{
Cause analysis and solutions of water blocking damage in cracked/ non-cracked tight sandstone gas reservoirs
}

\author{
Jie Wang ${ }^{1,2} \cdot$ Fu-Jian Zhou ${ }^{1,2}$
}

Received: 3 January 2020 / Published online: 6 July 2020

(c) The Author(s) 2020

\begin{abstract}
After hydraulic fracturing treatment, a reduction in permeability caused by the invasion of fracturing fluids is an inevitable problem, which is called water blocking damage. Therefore, it is important to mitigate and eliminate water blocking damage to improve the flow capacities of formation fluids and flowback rates of the fracturing fluid. However, the steady-state core flow method cannot quickly and accurately evaluate the effects of chemical agents in enhancing the fluid flow capacities in tight reservoirs. This paper introduces a time-saving and accurate method, pressure transmission test (PTT), which can quickly and quantitatively evaluate the liquid flow capacities and gas-drive flowback rates of a new nanoemulsion. Furthermore, scanning electron microscopy (SEM) was used to analyze the damage mechanism of different fluids and the adsorption of chemical agents on the rock surface. Parallel core flow experiments were used to evaluate the effects of the nanoemulsion on enhancing flowback rates in heterogeneous tight reservoirs. Experimental results show that the water blocking damage mechanisms differ in matrices and fractures. The main channels for gas channeling are fractures in cracked cores and pores in non-cracked cores. Cracked cores suffer less damage from water blocking than non-cracked cores, but have a lower potential to reduce water saturation. The PTT and SEM results show that the permeability reduction in tight sandstones caused by invasion of external fluids can be list as guar gum fracturing fluid $>$ slickwater $>$ brine. Parallel core flow experiments show that for low-permeability heterogenous sandstone reservoirs with a certain permeability ratio, the nanoemulsion can not only reduce reverse gas channeling degree, but also increase the flowback rate of the fracturing fluid. The nanoemulsion system provides a new solution to mitigate and eliminate water blocking damage caused by fracturing fluids in tight sandstone gas reservoirs.
\end{abstract}

Keywords Hydraulic fracturing · Water blocking damage $\cdot$ Nanoemulsion $\cdot$ Pressure transmission test $\cdot$ Liquid flow capacity $\cdot$ Flowback rate

\section{Introduction}

As the global demand for oil and gas increases, more and more advanced technologies are investigated to maximize production, such as horizontal well drilling and fracturing. Unconventional natural gas resources play an increasingly

Edited by Yan-Hua Sun

Fu-Jian Zhou

zhoufj@cup.edu.cn

1 Unconventional Natural Gas Institute, China University of Petroleum (Beijing), Beijing 102249, China

2 State Key Laboratory of Petroleum Resource and Prospecting, China University of Petroleum (Beijing), Beijing 102249, China important role in the current energy supply, meanwhile in unconventional reservoirs, new techniques are especially important to improve oil/gas recovery. At present, unconventional natural gas production in US accounts for more than $43 \%$ of the total gas production, of which the natural gas from tight sandstones accounts for approximately $70 \%$ and most reservoirs have not yet been developed (Khlaifat et al. 2011). Due to the low natural productivity of a single well, horizontal drilling and fracturing are used to promote reservoir stimulation, achieving economic exploitation. However, the fracturing fluid cannot flow back immediately and large amounts of fracturing fluids would retain in the formation, thereby damaging the formation permeability due to water blocking damage and then significantly reducing the productivity of gas wells (Bahrami et al. 2012; Dutta et al. 2012; Li et al. 2015, 2020; You et al. 2018; Zhang et al. 2018). 
Researchers have conducted extensive studies of the causes and solutions of water blocking damage in tight sandstone gas reservoirs. Because the drilling fluid, completion fluid, fracturing fluid, or other external fluids are difficult to flow back after invading during the exploitation of oil and gas reservoirs, the water saturation of the reservoir increases and the oil and gas phase permeabilities decrease, which is the definition of water blocking damage (Shao et al. 2010; Lei et al. 2017; Meng et al. 2019). The causes of water blocking damage in gas reservoirs can be divided into the following types: (1) Water phase permeability around the irreducible water is decline; (2) high capillary pressure of external fluids in the formation (Bybee 2007), and (3) gas flooding fingering issue caused by the reservoir heterogeneity. Currently, the main way to solve the water blocking problem is to alter the reservoir wettability by injecting chemicals into the formation. Li and Firoozabadi (2000) altered the rock wettability to gas-wet using fluorinated chemicals and studied the reduction in core liquid saturations through wetting angle tests, imbibition experiments, and steady-state core flow tests ( $\mathrm{Li}$ and Firoozabadi 2000). Since then, Noh and Firoozabadi used alcohol-based surfactants to alter the wettability of reservoir rocks (Noh and Firoozabadi 2008). Sharifzadeh et al. (2013) developed polymer surfactants containing fluorine groups to make the rock surfaces amphiphobic. Karandish et al. (2015) used anionic fluorine chemicals to improve the wettability of carbonate reservoirs and analyzed the adsorption properties of chemicals with SEM and EDX. Aminnaji et al. (2015), Gahrooei and Ghazanfari (2017) and Liu et al. (2015) used water-based fluorinated nanoemulsion to alter the wettability of carbonate and sandstone reservoirs and results showed that nanoemulsions altered the rock surfaces to be water- and oil-repellent and at the same time increased liquid mobility.

The above studies are based on the steady-state core flow method performed on high-permeability cores. However, when this method is used to test low-permeability cores, a long period of time is required to reach the equilibrium between the fluid and the core to make sure that Darcy's law is valid. Furthermore, microscale effects tend to exist in low-permeability rocks, decreasing the accuracy of this method (Liang et al. 2018; Zhang et al. 2019). This paper introduces the pressure transmission test (PTT), which can quickly and accurately evaluate the improvement of the new nanoemulsion in the gas flooding flowback effect and the liquid flow capacity in tight sandstone reservoirs. This method was first proposed by Brace et al. (1968) and used to measure the permeability of Westerly granite. Then several researchers improved the method in many respects and proposed a universal law of dimensionless pressure versus time, which has been widely used in the petroleum industry (Lin 1977; Hsieh et al. 1981; Dicker and Smits 1988). In addition, although surfactants can alter the gas-liquid surface tension and reservoir wettability, it cannot effectively mitigate the problem of gas channeling caused by heterogeneity. Therefore, there is still water remains in those relatively low-permeability zones, which affects gas well productivity. Nanoemulsions not only can effectively reduce the gas-liquid surface tension but also alter the surface wettability. At the same time, the nanoemulsions, with a specific particle size, preferentially enter high-permeability reservoirs and adsorb on sandstone surfaces, thus reducing the pore-throat diameters. This behavior improves the reservoir heterogeneity and mitigates the gas fingering (Wang et al. 2019a, b).

In this study, the relationships between gas permeability and water saturation are tested to determine the reasons for water blocking damage in both non-cracked and cracked tight sandstone cores. The basic physical and chemical properties of the nanoemulsion are evaluated, and its improvement in flow capacity of fracturing fluids is tested by PTT. Parallel core flow experiments are also conducted to evaluate whether the nanoemulsion can improve the flowback rate and the liquid capacity of gas flooding. The nanoemulsion provides a solution to removing water blocking damage in tight sandstone gas reservoirs.

\section{Experimental}

\subsection{Core preparation}

Experiments were performed on four types of core samples: (1) Low-permeability core samples and (2) cracked core samples were used to evaluate water blocking damage to tight sandstone reservoirs. The cracked core samples were made by manual splitting. (3) Parallel cores were a group of tight sandstone cores with different permeabilities and used to study the effect of nanoemulsion on improving reservoir heterogeneity and reducing the fingering of gas flooding. (4) Core samples used for the pressure transmission test (PTT) were taken from the same core column and their permeabilities are similar. All the cores were taken from the Dixi block in the Tarim Oilfield, with a depth of $4762.79 \mathrm{~m}$. The process of preparing core samples for pressure transmission test is shown in Fig. 1. Tables 1, 2 and 3 list the information about all core samples used in this study.

\subsection{Experimental fluids}

\subsubsection{Mimicked formation brine}

Mimicked formation brine ( $2.00 \mathrm{wt} \% \mathrm{KCl}$ solution) was used to measure the initial liquid permeability of core samples and also used to prepare other types of fluids. The density, viscosity, and salinity of the formation water are $1.02 \mathrm{~g} /$ $\mathrm{cm}^{3}, 1.01 \mathrm{mPa} \mathrm{s}$, and $20,000 \mathrm{mg} / \mathrm{L}$, respectively. 

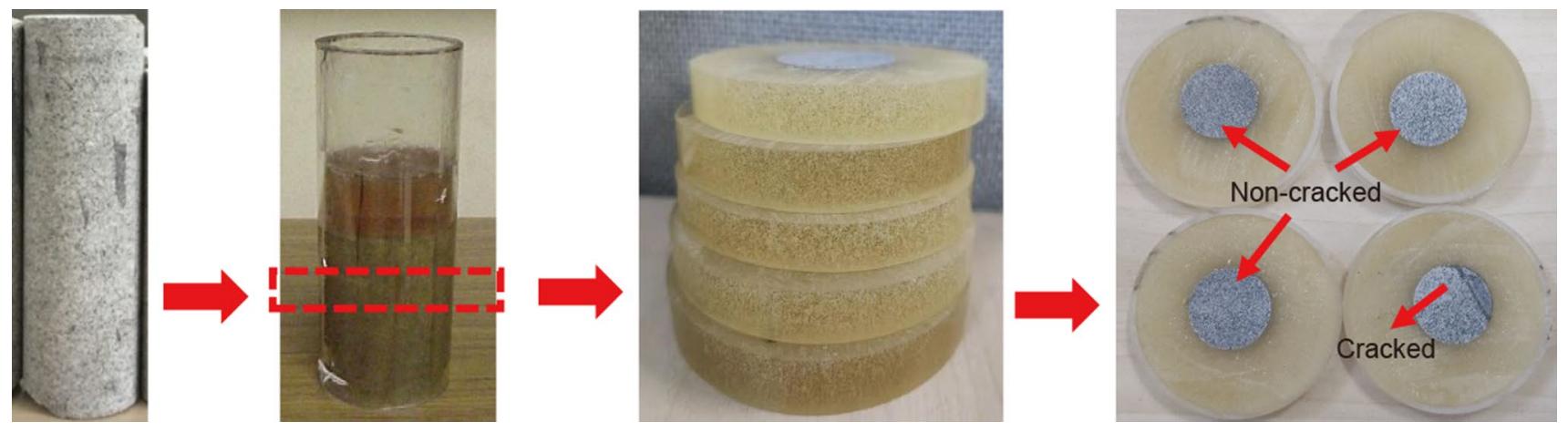

Fig. 1 The process of preparing core samples for pressure transmission tests

Table 1 Information on core samples used to evaluate water blocking damage

\begin{tabular}{lllllll}
\hline Core No. & Dimensions & & $\begin{array}{l}\text { Initial gas permeabil- } \\
\text { ity, } 10^{-3} \mu \mathrm{m}\end{array}$ & Porosity, $\%$ & Pore volume, $\mathrm{cm}^{3}$ & Test \\
\cline { 2 - 6 } & Diameter, cm & Length, $\mathrm{cm}$ & & & & \\
\hline 1 & 2.498 & 4.986 & 0.1785 & 3.112 & 0.7601 & Water block \\
2 & 2.496 & 4.987 & 0.3623 & 3.486 & 0.8502 & damage to \\
3 & 2.493 & 4.985 & 0.4848 & 3.213 & 0.7814 & non-cracked \\
4 & 2.499 & 4.989 & 64.50 & 5.245 & 1.2828 & Water block \\
5 & 2.498 & 4.987 & 92.40 & 6.263 & 1.5299 & damage \\
6 & 2.501 & 4.983 & 146.21 & 7.125 & 1.7433 & to cracked \\
7 & 2.498 & 4.989 & 250.40 & 8.231 & 2.0115 & cores \\
\hline
\end{tabular}

Table 2 Information on core samples used in parallel core flow experiments

\begin{tabular}{|c|c|c|c|c|c|}
\hline \multirow[t]{2}{*}{ Core No. } & \multicolumn{2}{|l|}{ Dimensions } & \multirow{2}{*}{$\begin{array}{l}\text { Initial liquid permeability (brine with- } \\
\text { out nanoemulsion), } 10^{-3} \mu \mathrm{m}\end{array}$} & \multirow[t]{2}{*}{ Porosity, \% } & \multirow[t]{2}{*}{ Pore volume, $\mathrm{cm}^{3}$} \\
\hline & Diameter, cm & Diameter, cm & & & \\
\hline $\mathrm{P}-1 / \mathrm{H}$ & 2.493 & 4.989 & 0.2158 & 5.328 & 1.2969 \\
\hline $\mathrm{P}-1 / \mathrm{L}$ & 2.496 & 4.987 & 0.03459 & 4.432 & 1.0809 \\
\hline $\mathrm{P}-2 / \mathrm{H}$ & 2.498 & 4.989 & 0.6936 & 5.835 & 1.4260 \\
\hline $\mathrm{P}-2 / \mathrm{L}$ & 2.499 & 4.986 & 0.08112 & 3.389 & 0.8284 \\
\hline $\mathrm{P}-3 / \mathrm{H}$ & 2.498 & 4.987 & 1.6102 & 6.387 & 1.5602 \\
\hline $\mathrm{P}-3 / \mathrm{L}$ & 2.501 & 4.987 & 0.2182 & 4.394 & 1.0760 \\
\hline
\end{tabular}

Table 3 Information on core samples used in PTT

\begin{tabular}{|c|c|c|c|c|c|}
\hline \multirow[t]{2}{*}{ Core No. } & \multicolumn{2}{|l|}{ Dimensions } & \multirow{2}{*}{$\begin{array}{l}\text { Initial liquid permeability (working fluid } \\
\text { without nanoemulsion), } 10^{-3} \mu \mathrm{m}\end{array}$} & \multirow[t]{2}{*}{ Porosity, \% } & \multirow[t]{2}{*}{ Pore volume, $\mathrm{cm}^{3}$} \\
\hline & Diameter, $\mathrm{cm}$ & Diameter, cm & & & \\
\hline PTT-1 & 2.496 & 0.987 & 0.0142 & 4.213 & 0.2034 \\
\hline PTT-2 & 2.498 & 0.986 & 0.0077 & 3.113 & 0.1504 \\
\hline PTT-3 & 2.499 & 0.992 & 0.0031 & 3.431 & 0.1669 \\
\hline PTT-4 & 2.493 & 0.989 & 0.0008 & 3.032 & 0.1669 \\
\hline
\end{tabular}




\subsubsection{Nanoemulsion}

The nanoemulsion was prepared at room temperature and the procedures are as follows: firstly, polyoxyethylene ether surfactants, cyclohexane, and water were mixed in a mass ratio of 1:2:2; then the mixture was placed in an ultrasonic vibrator and shaken at $100 \mathrm{~Hz}$ for $15 \mathrm{~min}$ to form an oil-in-water emulsion. Among them, the dispersed phase is cyclohexane (oil), the continuous phase is water, and the surfactant belongs to pure substance polyoxyethylene ethers. As the nanoemulsion is synthesized from microemulsion, so it has long-term stability at room temperature (Eastoe et al. 1990), which will benefit transportation and fluid preparation. The synthetic method is shown in Fig. 2.

\subsubsection{Hydraulic fracturing fluids}

The slickwater fracturing fluid (SWF) is composed of $0.05 \mathrm{wt} \%$ drag reducer and $2.00 \mathrm{wt} \% \mathrm{KCl}$, which is prepared based on the formulation used in oil fields. The viscosity of slickwater is $1.12 \mathrm{mPa}$ s, which is close to that of water.

The guar gum fracturing fluid (GGF) includes $0.50 \mathrm{wt} \%$ hydroxypropyl guar gum, $0.30 \mathrm{wt} \%$ crosslinking stabilizer, $0.40 \mathrm{wt} \%$ crosslinker, $0.10 \mathrm{wt} \%$ gel breaker, and $2.00 \mathrm{wt} \%$ $\mathrm{KCl}$ powder, which is prepared based on the formulation used in oil fields.

Two sets of fluids were prepared for each fracturing fluid in this study. The first set of fluids was prepared based on the formulation used in oil fields, i.e., without any nanoemulsion. The second sets of fracturing fluids were prepared by adding nanoemulsion to the first set of fluids to evaluate the effect of nanoemulsion on the removal of water blocking damage, in which the nanoemulsion concentration was $0.30 \mathrm{wt} \%$ in the fracturing fluid.

Before use the two sets of guar gum fracturing fluid were placed in a water bath and heated at $80^{\circ} \mathrm{C}$ for $4 \mathrm{~h}$ until the gel was completely broken up. The unbroken guar gum fracturing fluid had a stable viscosity of $100 \mathrm{mPa}$ s after shearing at
$170 \mathrm{~s}^{-1}$ for $1 \mathrm{~h}$ at $120{ }^{\circ} \mathrm{C}$. The broken fracturing fluid had a viscosity of $1.25 \mathrm{mPa}$.

\subsection{Experimental methods and procedures}

\subsubsection{Water blocking damage evaluation}

Hydraulic fracturing is a process through which a large number of fractures of various sizes are created in the rock. These fractured fractures and the natural micro-fractures allow the natural gas and/or crude oil trapped in formations to move to the wellbore. The damage caused by water retention is different in the reservoir matrix and fractures. It is necessary to investigate the differences in water blocking damage to reservoir matrix (uncracked cores) and fractures (cracked cores).

The experimental procedures for evaluating water blocking damage are as follows:

1. The core sample was saturated with $2.00 \mathrm{wt} \% \mathrm{KCl}$ brine for $24 \mathrm{~h}$ by the vacuum method.

2. The brine-saturated core sample was installed into the core holder and then 3-5 pore volume (PV) of $\mathrm{KCl}$ brine was continuously injected to ensure that the core sample was completely saturated.

3. The saturated core sample was centrifuged with a centrifuge LXJ02 at 3000-20,000 RPM. The core sample was removed at different centrifugation times to measure the core weight for calculating the residual water saturation. And then wet $\mathrm{N}_{2}$ was used to measure the core permeability $k_{\mathrm{D}}$ (STY-2 gas permeability tester) at different water saturations.

The corresponding permeability damage rate $(D)$ was calculated from Eq. (1).

$D=\left(k_{0}-k_{\mathrm{D}}\right) / k_{0} \times 100 \%$

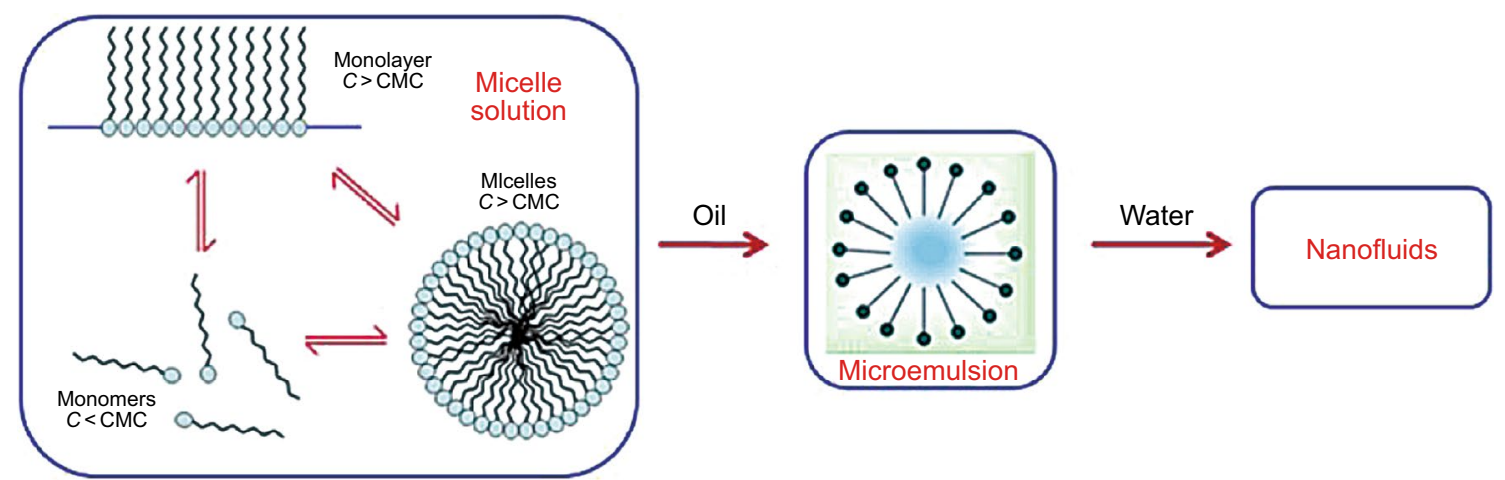

Fig. 2 Map for the synthetic method of nanoemulsion 
where $k_{0}$ is the initial permeability of the core sample (at water saturation of 0$), 10^{-3} \mu \mathrm{m}^{2} ; k_{\mathrm{D}}$ is the core permeability at different water saturations.

For the cracked core samples, the confining pressure is required to be controlled to ensure that the crack widths remained the same at each stage.

\subsubsection{Characterization of nanoemulsions}

The size of droplets in the nanoemulsion was characterized using a Zetasizer Nano laser particle size analyzer. A JYW200A surface/interfacial tensiometer was used to determine the nanoemulsion surface tensions at different concentrations. A $\mathrm{JY}-\mathrm{PHb}$ contact angle tester was used to measure the contact angles of water on the surface of the cores after being soaked in different concentration nanoemulsions for $24 \mathrm{~h}$.

\subsubsection{Pressure transmission test}

Because of low permeability and tight structure of the target reservoir, it is difficult to accurately measure its permeability by the common steady-state core flow experiments. Therefore, the pressure transmission test (PTT) (Dicker and Smits 1988; Zhang et al. 2019) was used to evaluate the permeability damage caused by fracturing fluids. Figure 3 shows a schematic diagram of PTT setup.

During testing, the downstream pressure remained unchanged while the upstream pressure responses were recorded. The PTT method significantly reduces test times by measuring pressure declines rather than the fluid flow velocities through the core (Dicker and Smits 1988; Zhang et al. 2019). The core permeability can be calculated according to the transient pressure model:

$k=-\frac{\mu C V L}{A} \frac{\mathrm{d} \lambda}{\mathrm{d} t}=-a \frac{\mu C V L}{A}$

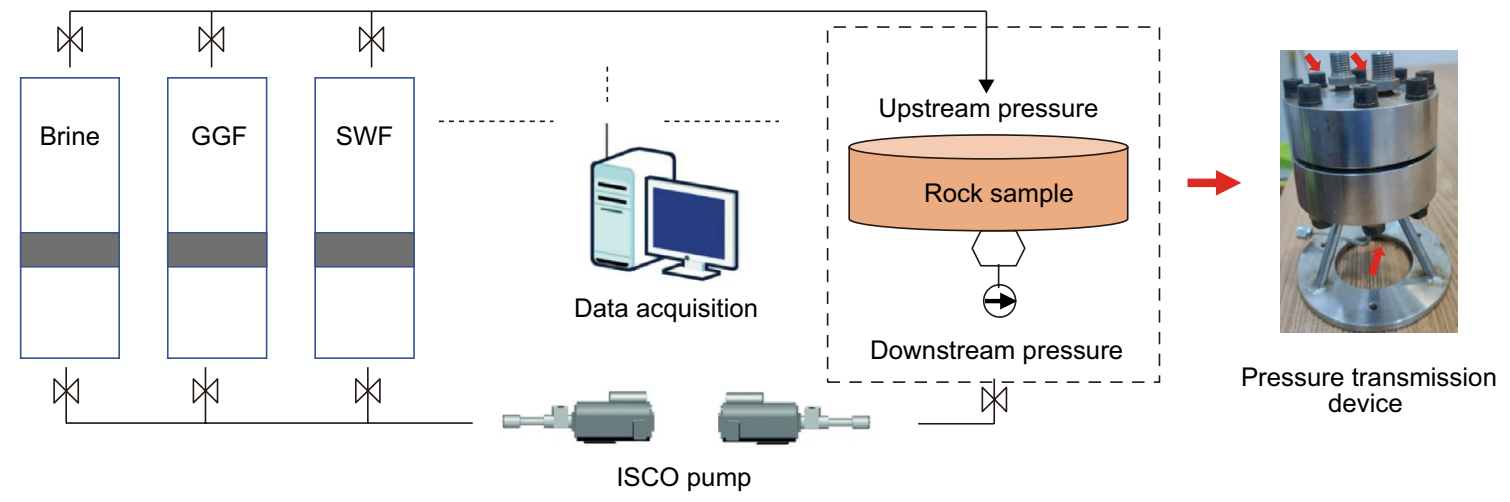

$\lambda=\ln \left(\frac{P_{\mathrm{D}}-P_{\mathrm{L}, t}}{P_{\mathrm{D}}-P_{\mathrm{L}, 0}}\right)$

where $k$ is the core sample permeability, $10^{-3} \mu \mathrm{m}^{2} ; \mu$ is the test fluid viscosity, $\mathrm{mPa}$; $C$ is the compression coefficient of the test fluid, $\mathrm{MPa}^{-1} ; V$ is the volume of the downstream sealed chamber, $\mathrm{mL} ; L$ is the core sample thickness, $\mathrm{cm}$; $A$ is the cross-sectional area of the core sample, $\mathrm{cm}^{2} ; \lambda$ is the dimensionless pressure; $a$ is the curve slope between the dimensionless pressure and time and is obtained by the linear fitting method; $P_{\mathrm{D}}$ is the downstream pressure, MPa; $P_{\mathrm{L}, 0}$ is the initial upstream pressure, $\mathrm{MPa}$; and $P_{\mathrm{L}, t}$ is the upstream pressure over time, MPa.

Brine, guar gum fracturing fluid, and slickwater are commonly used as working fluids during fracturing tight sandstone reservoirs. The water blocking damage caused by the above-mentioned fluids and the effects of the novel nanoemulsion on the fluid flow capacity were studied. The main experimental procedures are as follows:

1. The core sample was saturated with brine with the vacuum method.

2. The PTT device was installed, the working fluids were poured into the intermediate containers, and the core sample was installed into the core holder. Then the upstream and downstream of the core holder was evacuated for $60 \mathrm{~min}$.

3. Brine was pumped into the upstream sealed chamber using an ISCO pump. A constant injection pressure was set at $0.05-0.1 \mathrm{MPa}$ and the pressure was recorded as $P_{\mathrm{L}, 0}$.

4. The working fluid was injected into the downstream sealed chamber with an ISCO pump. The injection pressure was kept constant $(0.5-1.0 \mathrm{MPa})$ and recorded as $P_{\mathrm{D}}$. During the whole process, the upstream pressures $P_{\mathrm{L}, t}$ were monitored and recorded over time.

5. The relationship curve of the dimensionless pressure $\lambda$ with time was drawn and the slope $(a)$ of the curve was

Fig. 3 Schematic diagram of pressure transmission test 
obtained. The core permeabilities at different experiment stages (such as injection of brine/brine with nanoemulsion, SWF/SWF with nanoemulsion and broken GGF/ broken GGF with nanoemulsion) were calculated according to Eq. (2). The improvement of liquid permeability was calculated according to Eq. (4).

$R=\left(k_{\mathrm{D} 0}-k_{\mathrm{D} 1}\right) / k_{\mathrm{D} 0} \times 100 \%$

where $k_{\mathrm{D} 0}$ is the liquid permeability of the core sample tested by working fluids (brine/SWF/GGF) without nanoemulsion, $10^{-3} \mu \mathrm{m}^{2}$; and $k_{\mathrm{D} 1}$ is the improved core permeability tested by working fluids with nanoemulsion.

6. After the experiment, the core was dried at $80{ }^{\circ} \mathrm{C}$ for $48 \mathrm{~h}$ and SEM scanning was performed on the dried core sample to observe damage to its microstructure.

\subsubsection{Parallel core flow test}

Actual tight sandstone reservoirs are heterogeneous. It is necessary to evaluate whether the nanoemulsion can improve reservoir heterogeneity and reduce fingering during gas flooding. Therefore, the effects of the nanoemulsion on reducing gas flood fingering were tested with the parallel core flow device. The parallel core flow device, as shown in Fig. 4, mainly consists of a nitrogen gas source, an ISCO pump, intermediate containers, two core holders in parallel (one for high-permeability core, and another for low-permeability core), pressure sensors, and a data acquisition system.

Parallel core flow experiments were used to evaluate the effect of the nanoemulsion on the sandstone heterogeneity and liquid flowback rates, which is simulated gas exploitation after fracturing. The experimental procedures are as follows:

1. Two types of core samples with different fluid permeabilities were installed into two core holders.

2. A confining pressure of $5 \mathrm{MPa}$ was applied by a hand pump.

3. Fluid was injected into the cores at a rate of $0.15 \mathrm{~mL} /$ min. The injection volume of the fluid was greater than $1 \mathrm{PV}$, and injection continued until the pressure reached steady state. During the injection process, the pressure gradient was recorded by pressure sensors and a data acquisition system. Meanwhile, during each stage of displacement, nitrogen was used to displace the saturated core, and then the core was taken out and weighed to calculate the gas flooding flowback rate at different stages.

\section{Results and discussion}

\subsection{Water blocking damage}

\subsubsection{Low-permeability non-cracked cores}

During fracturing, fracturing fluids enter the non-cracked core through fractures and cause damage to the reservoir. The gas permeabilities of core samples at different water saturations were determined to illustrate the effect of water saturation on permeability. As shown in Fig. 5, the gas permeability in the gas-liquid flow state decreases gradually as the water saturation increases. Meanwhile, the lower the initial gas permeability, the greater the gas permeability decreases in the process of water saturation increasing.

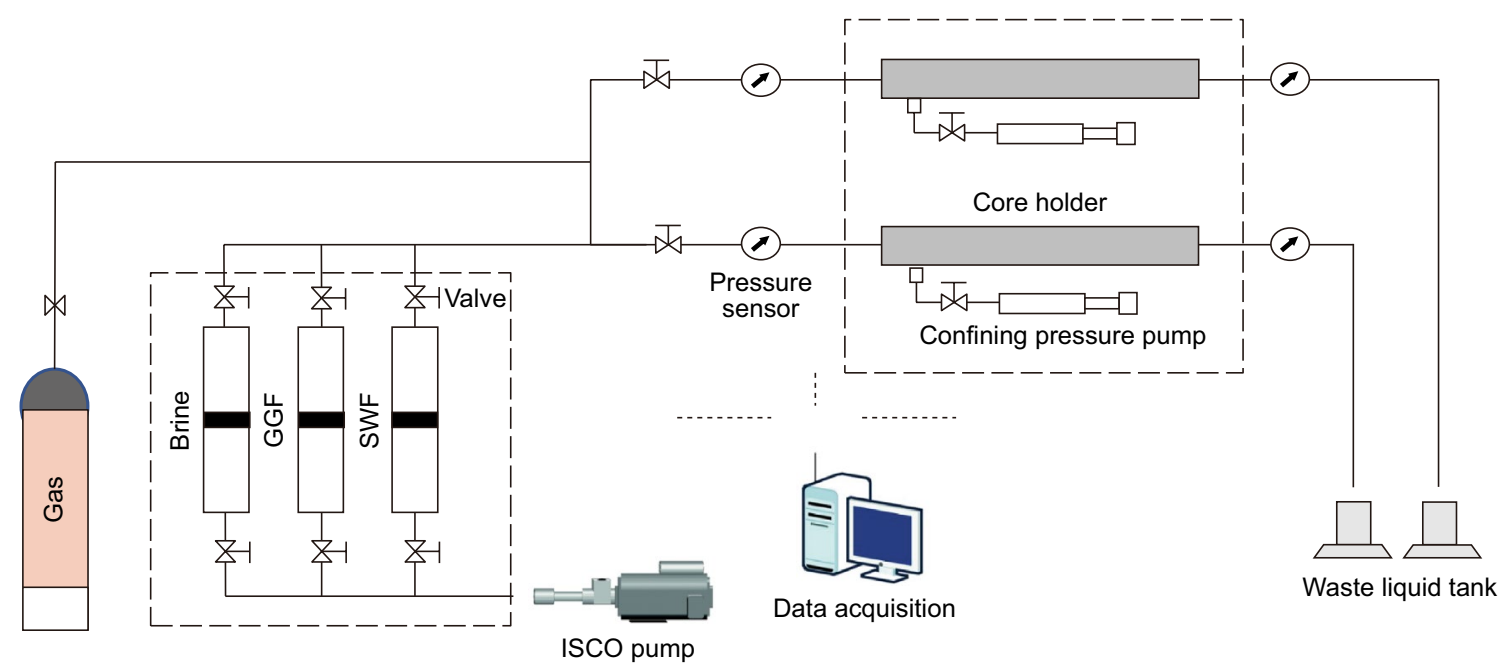

Fig. 4 Schematic diagram of the high-temperature and high-pressure parallel core flow device 


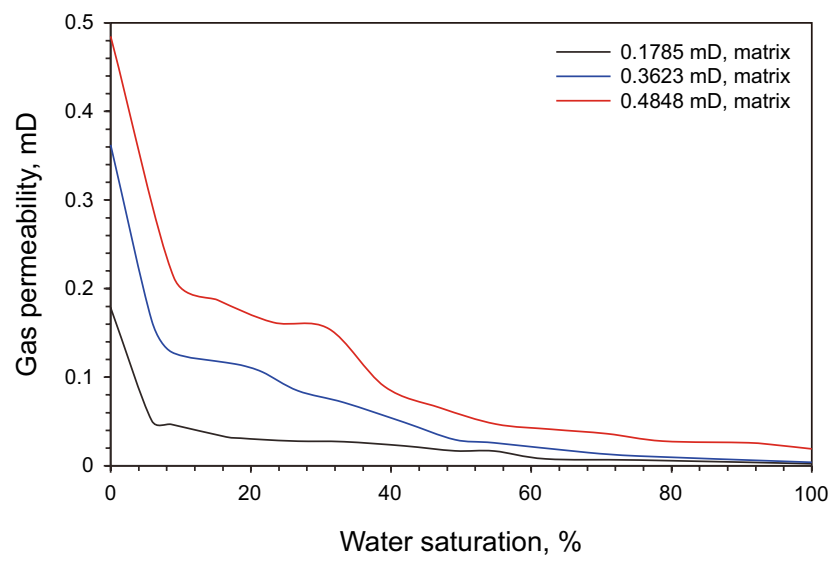

Fig. 5 Gas permeabilities of non-cracked cores at different water saturations

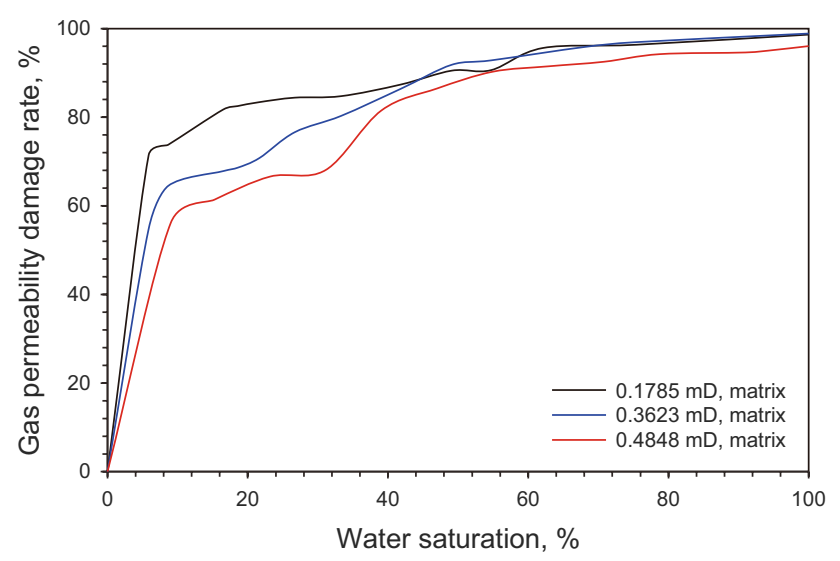

Fig. 6 Gas permeability damage rates of non-cracked cores at different water saturations

The permeability damage rates were calculated from Eq. (1) and the results are shown in Fig. 6. When the water saturation of the non-cracked core samples is approximately $10 \%$, the growth rate of the gas permeability damage is the highest (more than 50\%). As the water saturation further increases, the increase in the core gas permeability damage rate gradually becomes flat. When the water saturation reaches $80 \%$, the gas permeability damage rate reaches $95 \%$ or more.

\subsubsection{Cracked cores}

During the reservoir stimulation, external fluids preferentially enter the fractures formed during hydraulic fracturing and gradually flow into the rock matrix. Therefore, it is necessary to study the damage degree in non-cracked cores and cracked cores. The cracked cores were created by artificial splitting and the gas permeabilities at different water saturations were measured. The experimental results are shown

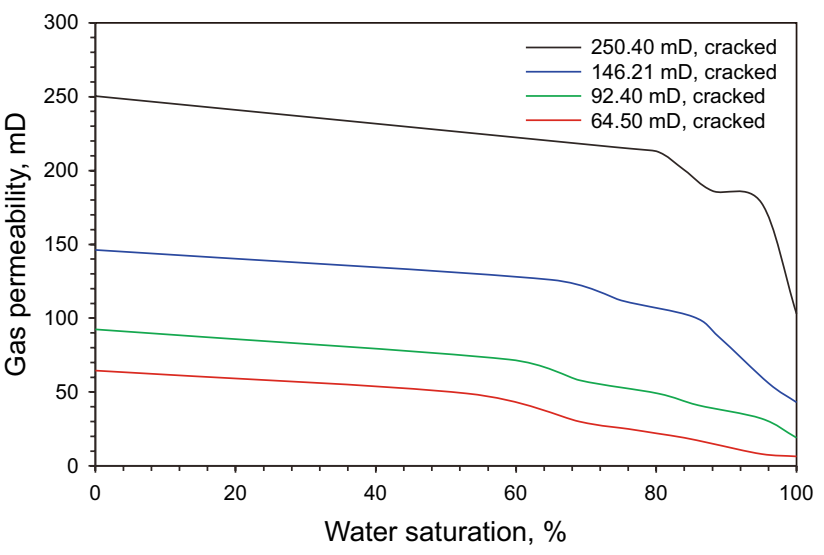

Fig. 7 Gas permeabilities of cracked cores at different water saturations

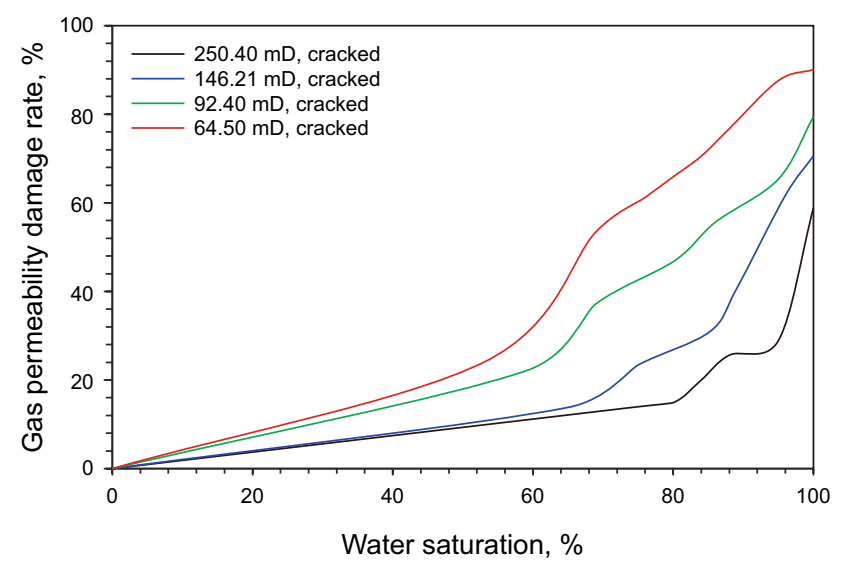

Fig. 8 Gas permeability damage rates of cracked cores at different water saturations

in Fig. 7. Gas permeabilities show turning point only when the water saturation is higher than $50 \%$. Figure 8 shows the relationship between gas permeability damage rate and water saturation in cracked cores. When the water saturation is below $50 \%$, the gas permeability damage rate is less than $20 \%$, which is far lower than the damage to the non-cracked core at the same water saturation.

A comparison of water blocking damage to rock matrix (non-cracked cores) and cracked cores indicates that with an increase in water saturation, there is a significant difference between the decreasing trends in gas permeabilities of the non-cracked and cracked cores. There is also a great difference between the damage rates of these two types of cores. The pores and throats in the non-cracked cores are the main channels for fluid flow. It is believed that after the pores and throats are filled with water, the gas flow capacity is reduced. At the same time, the gas-liquid phase forms additional resistance (e.g., the Jamin effect) in the tortuous pore throats, which further increases gas 
flow resistance. Therefore, when the water saturation in the non-cracked core is low, the damage rate to the gas permeability is remarkably high. However, for the cracked cores fractures are the main channels for fluid flow, so when the water blocking in fractures is removed, the gas channeling through the cracked core is reduced, and the cores has a lower rate of damage. The lower the gas permeabilities of cracked cores, the lower the degrees of gas channeling when gas displaces water in the fractures, the higher the damage rate of water on gas permeability.

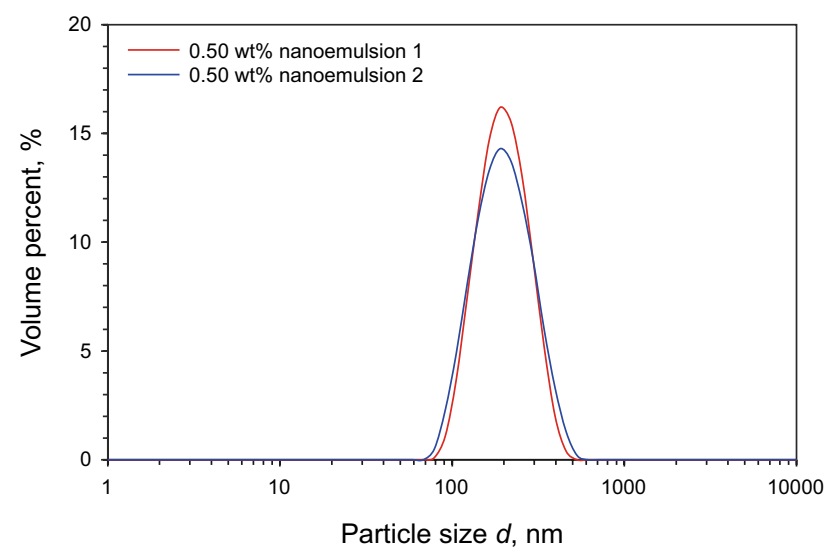

Fig. 9 Size distribution of nanoparticles in $0.50 \mathrm{wt} \%$ nanoemulsion. Reprint permission obtained from Wang et al. (2019a, b)

\subsection{Characteristics of the nanoemulsion}

The size distributions of $0.5 \mathrm{wt} \%$ nanoemulsions are shown in Fig. 9, and the nanoparticle sizes were measured $160.8 \mathrm{~nm}$ and $160.9 \mathrm{~nm}$, respectively (Wang et al. 2019).

To determine the optimum concentration of nanoemulsion for altering rock wettability, core slices were soaked in nanoemulsions of different concentrations for $24 \mathrm{~h}$, and then the "air-water-core" contact angles were measured. As shown in Fig. 10, when no nanoemulsion is added to the soaking fluid, the water droplet on the solid surface spreads out directly. The "air-water" contact angle increases with an increase in nanoemulsion concentration, reaching the peak value of $112.9^{\circ}$ at a concentration of $0.30 \mathrm{wt} \%$. This means the sandstone surfaces have completely altered from water wet to gas wet. Therefore, $0.30 \mathrm{wt} \%$ was the optimum concentration for the nanoemulsions. In addition, the surface tension of "air-water" is $72.71 \mathrm{mN} / \mathrm{m}$. When the concentration of the nanoemulsion was increased from $0.05 \mathrm{wt} \%$ to $0.30 \mathrm{wt} \%$, the surface tension of "air-watercore" only decreased from 31.08 to $29.04 \mathrm{mN} / \mathrm{m}$, as shown in Fig. 11. However, when the nanoemulsion concentration increased from 0 to $0.05 \mathrm{wt} \%$, the surface tension decreases by $41.63 \mathrm{mN} / \mathrm{m}$, indicating a significant effect of reducing the "air-water" surface tension compared with water.

Nanoemulsions have droplets with diameter on the order of $100 \mathrm{~nm}$ and can reduce the surface tension between air and water. The droplets in the nanoemulsion preferentially enter the relatively high-permeability regions in low-permeability reservoirs, and then adsorbed on the pore surface to

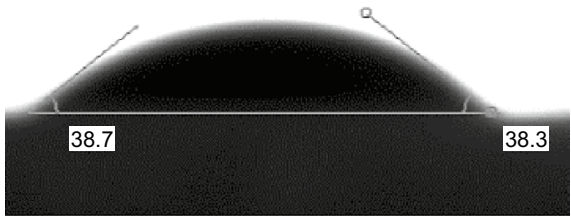

$0.05 \mathrm{wt} \%$ nanoemulsion, $38.5^{\circ}$

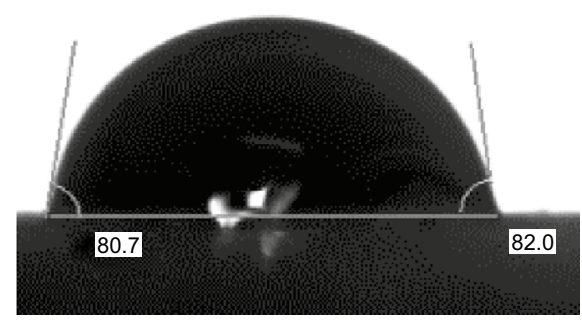

$0.20 \mathrm{wt} \%$ nanoemulsion, $81.4^{\circ}$

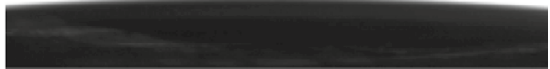

$0.00 \mathrm{wt} \%$ nanoemulsion, $0^{\circ}$

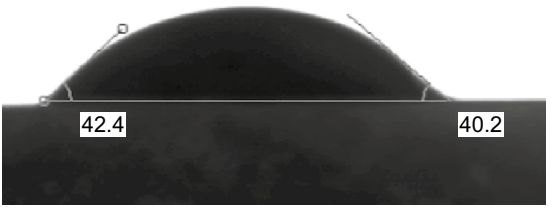

$0.10 \mathrm{wt} \%$ nanoemulsion, $41.3^{\circ}$

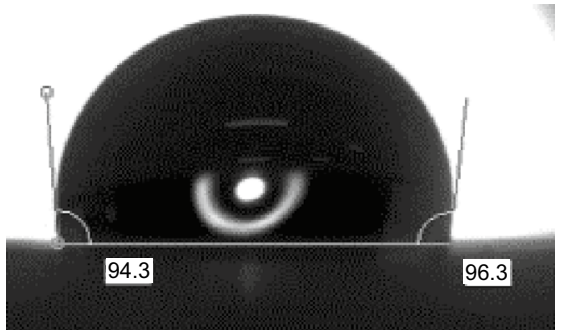

0.25 wt $\%$ nanoemulsion, $95.3^{\circ}$

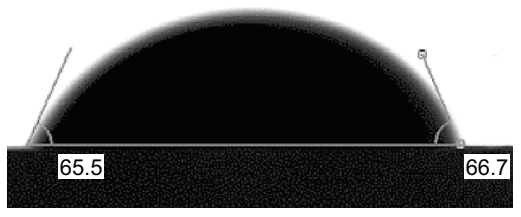

$0.15 \mathrm{wt} \%$ nanoemulsion, $66.1^{\circ}$

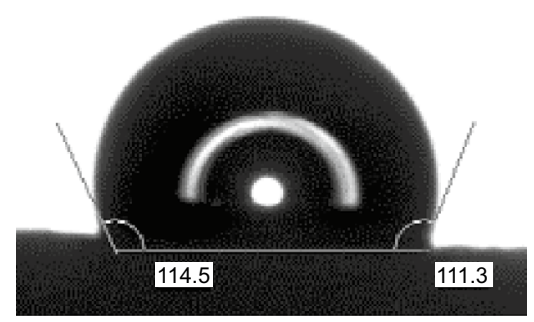

$0.30 \mathrm{wt} \%$ nanoemulsion, $112.9^{\circ}$

Fig. 10 "Air-water-core" contact angles after the core slices were soaked in different concentration nanoemulsions for $24 \mathrm{~h}$ 


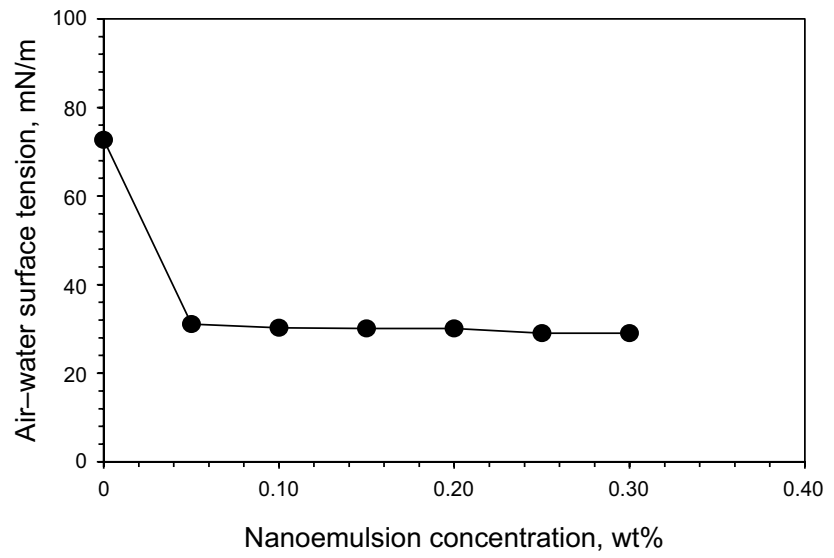

Fig. 11 Surface tensions of nanoemulsion fluids with different concentrations

lower its inner diameter and reduce the heterogeneity of lowpermeability reservoirs (Wang et al. 2019a, b). Therefore, when the gas in the reservoir displaces the external fluid to flow back to the wellbore after well completion, the nanoemulsion can effectively mitigate or eliminate gas fingering and increase the gas displacing efficiency. At the same time, the nanoemulsion can alter the wettability of the solid surfaces from hydrophilic to hydrophobic, which is beneficial for removing water blocking damage. These properties make nanoemulsions attractive in the oilfield industry.

\subsection{Removal of water blocking by nanoemulsion}

\subsubsection{PTT results}

The permeability of tight sandstone reservoirs is mainly influenced by fracturing fluids such as brine, guar, and slickwater. To study whether the nanoemulsion improves the liquid flow capacity, a series of experiments were performed to evaluate the core permeability changes before and after the nanoemulsion was added. Experimental data on different core types and PTT results are shown in Table 4 and Fig. 12. According to these results, when natural micro-fractures exist in the core, the improvement effect of the nanoemulsion on the liquid permeability is weaker than that for the non-cracked core. Therefore, the liquid flow capacity for micro-fracture cores increased by $54.28 \%$ while by $118.55 \%$ for the non-cracked core. In addition to water blocking damage, there also exists polymer or solid phase damage in slickwater and guar gum fracturing fluids (Liang et al. 2018; Zhang et al. 2019). Nanoemulsions cannot remove the damage caused by polymer adsorption or by solid phase retention. Therefore, in the non-cracked core, the increment in the liquid flow capacities of slickwater $(68.35 \%)$ and guar gum fracturing fluid $(61.21 \%)$ are lower than that for brine. Solid-phase residues exist after guar gum fracturing fluid is broken, so the increase in liquid flow capacity is $7.14 \%$ lower than for slick water.

\subsubsection{Damage mechanism and adsorption of chemical agents in different working fluids}

The core samples after PTT in Sect. 2.3.3 were placed in an oven at $80{ }^{\circ} \mathrm{C}$. After drying for $48 \mathrm{~h}$ the samples were removed and scanned with a GeminiSEM 300/VP high resolution field emission scanning electron microscope (SEM). Figure 13 shows that after the PPT experiments, the core morphology presents a specific angle. On the other hand, the core was destroyed by the polymer or solid phase residues in the slickwater and the guar gum fracturing fluid after the flow experiment, the micro-morphology was relatively cracked, which affected the permeability recovery. Figure 14 shows the adsorption of carbon element on the rock surfaces, which is the main element of nanoemulsion, slickwater, and guar gum. In the brine flow experiment, only nanoemulsion is adsorbed on the rock surface. However, in other workingfluid flow experiments, nanoemulsion, slickwater or guar

Table 4 The improvement in liquid flow capacity by the addition of nanoemulsion to working fluids

\begin{tabular}{llllll}
\hline Core No. & Core type & Working fluid type & $\begin{array}{l}\text { Nanoemulsion concentra- } \\
\text { tion in working fluid, wt } \%\end{array}$ & $\begin{array}{l}\text { Permeability after working } \\
\text { fluid treatment, } 10^{-3} \mu \mathrm{m}\end{array}$ & $\begin{array}{l}\text { Improvement of liquid permeability } \\
\text { by the addition of nanoemulsion, } \%\end{array}$ \\
\hline PPT-1 & Cracked & Brine & 0 & 0.0142 & 54.28 \\
& & & 0.30 & 0.0219 & 118.55 \\
PPT-2 & \multirow{2}{*}{ Non-cracked } & Brine & 0 & 0.0077 & 68.35 \\
& & & 0.30 & 0.0169 & 6.0031 \\
PPT-3 & \multirow{2}{*}{ Non-cracked } & SWF & 0.30 & 0.0052 & 61.21 \\
& & & 0 & 0.0008 & 0.0012 \\
\hline
\end{tabular}

Parameters in the PTT model: $V=2.35 \mathrm{~mL} ; L=0.65 \mathrm{~cm} ; A=4.91 \mathrm{~cm}^{2} ; \mu_{\mathrm{b}}=1.08 \mathrm{mPa} \mathrm{s} ; \mu_{\mathrm{s}}=1.25 \mathrm{mPa} \mathrm{s} ; \mu_{\mathrm{g}}=1.15 \mathrm{mPa} \mathrm{s} ; C=3.87 \times 10^{-5} \mathrm{MPa}^{-1}$. $\mu_{\mathrm{b}}$ : brine viscosity, $\mu_{\mathrm{s}}$ : slickwater viscosity, $\mu_{\mathrm{g}}$ : guar gum fracturing fluid viscosity after broken 


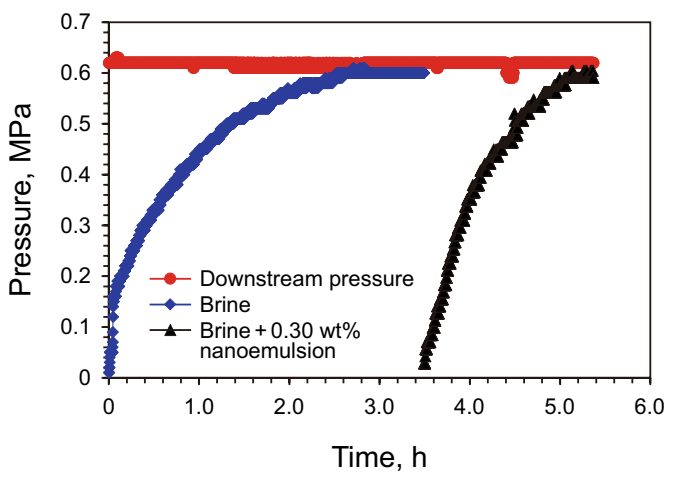

Time, $\mathrm{h}$

(a) Brine, cracked core sample
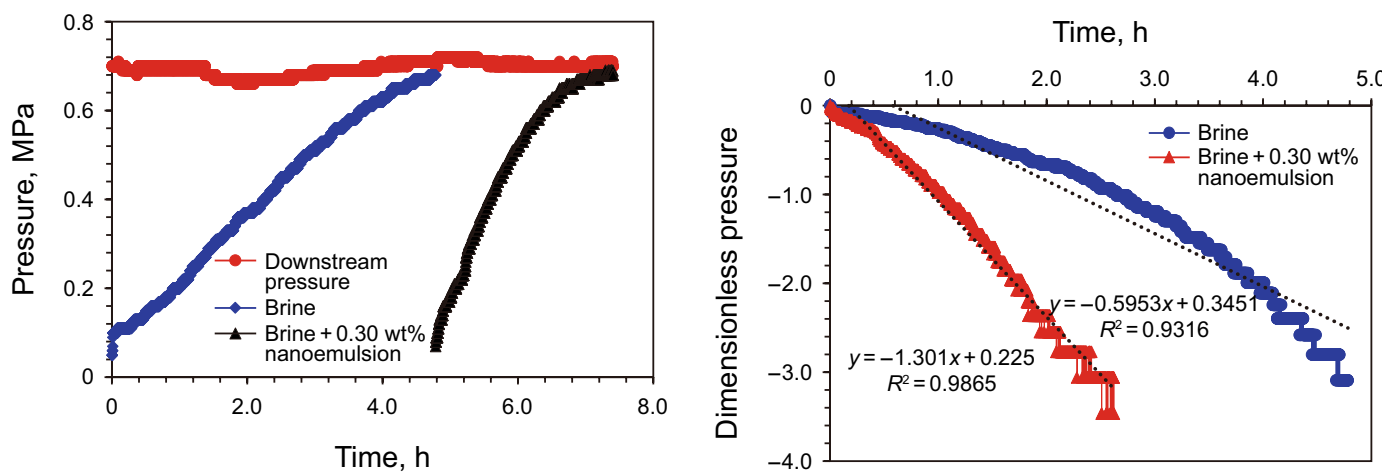

(b) Brine, non-cracked core sample
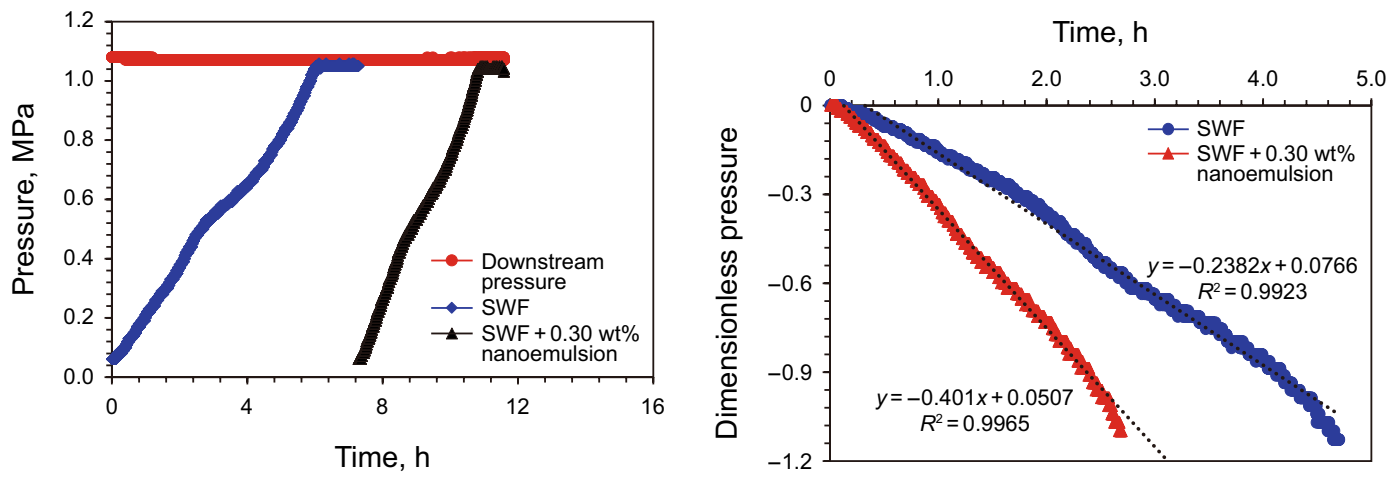

(c) SWF, non-cracked core sample
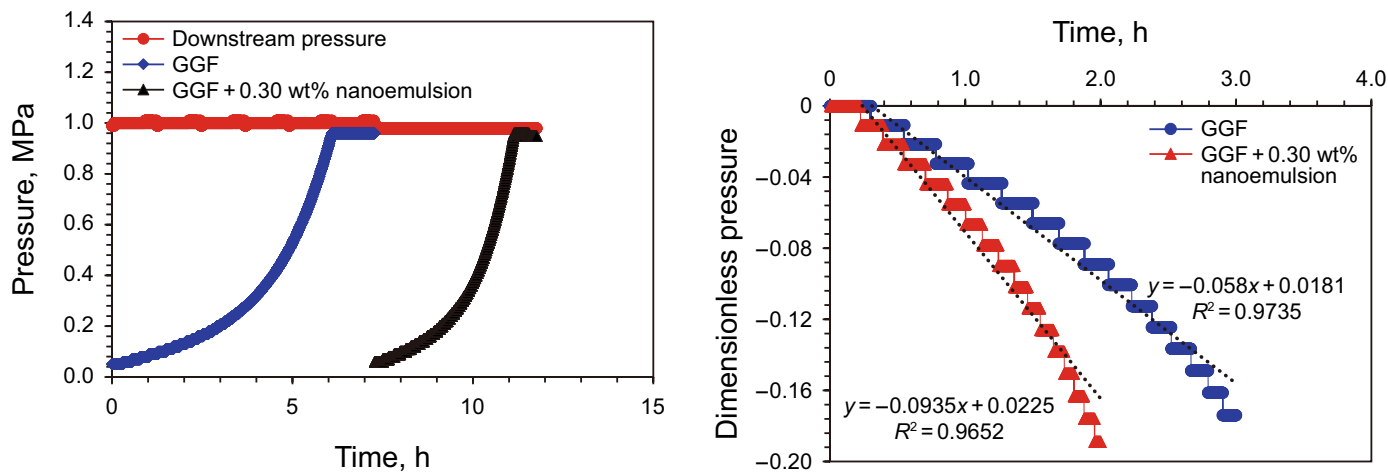

(d) Broken GGF, non-cracked core sample

Fig. 12 Pressure transmission curves and graphical slope interpretation of dimensionless pressure versus time 


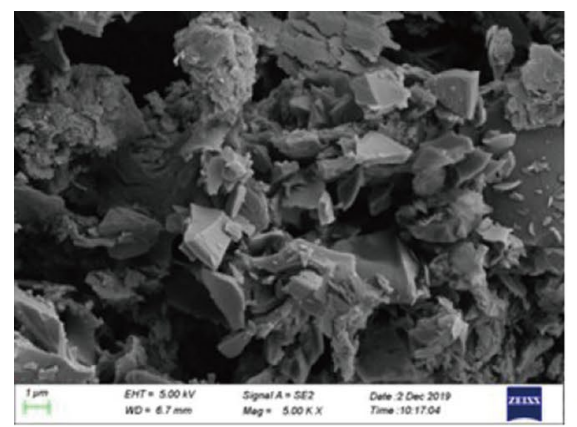

(a) Brine

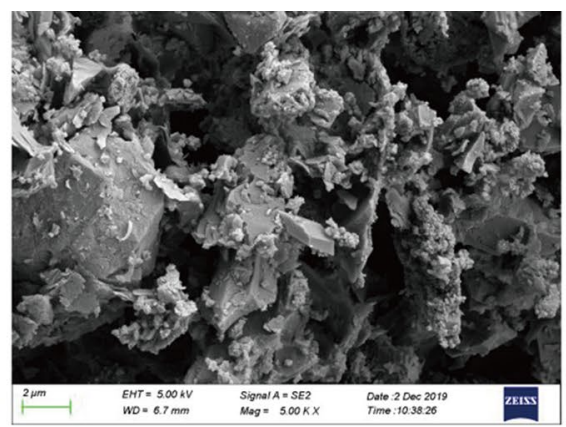

(b) SWF

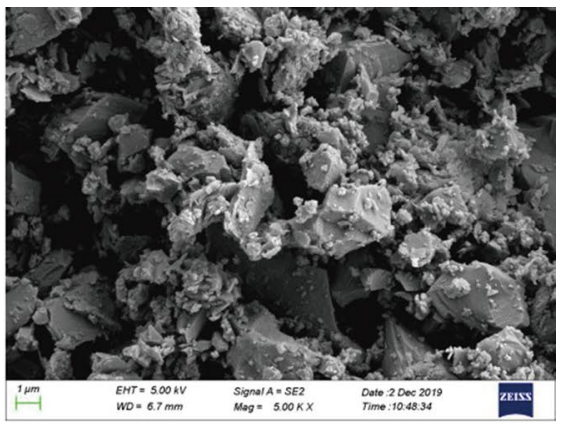

(c) GGF

Fig. 13 SEM images of core samples after PTT performed with different working fluids with nanoemulsion

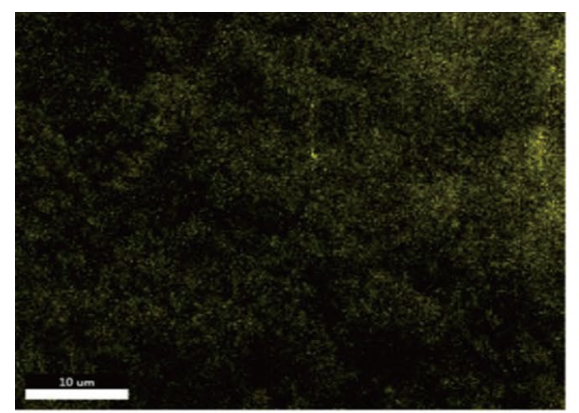

(a) Brine

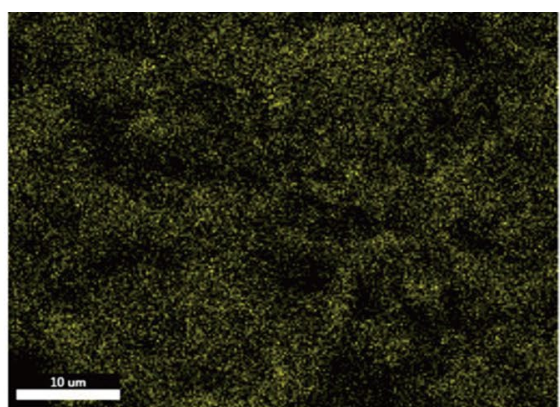

(b) SWF

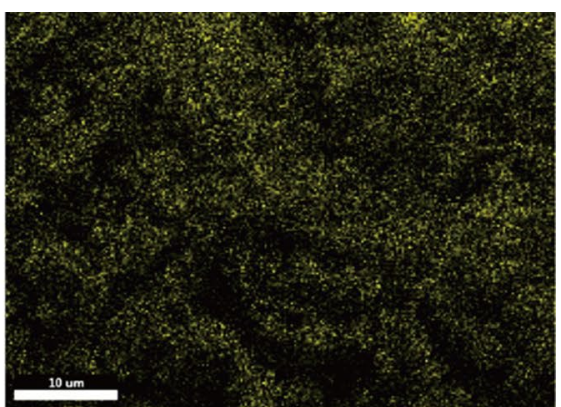

(c) GGF

Fig. 14 Carbon adsorption maps of rock surfaces after PTT performed with different working fluids with nanoemulsion

gum residues are absorbed on the rock surfaces. Therefore, the element adsorption pictures of slickwater and guar gum fracturing fluid shows the brightness of yellow and distribution are higher than that in the brine, which further verifies the damage of slickwater and guar gum fracturing fluid.

\subsubsection{Parallel core flow test results}

According to the PTT results, nanoemulsions can improve the flow capacity of brine, slickwater, and guar gum fracturing fluid in a degree. Therefore, it is necessary to further study whether the addition of nanoemulsions to the fracturing fluids can improve the flowback rate of the fracturing fluids. Because the actual reservoirs are often heterogeneous, the adaptability of nanoemulsions in reservoirs needs to be further studied. Two cores with different permeabilities were installed into parallel core holders to simulate a heterogeneous reservoir and then fluids were injected, separately. According to the injection pressure difference before and after fluids passed through the parallel cores, the fluid permeabilities, permeability contrast (ratio of the permeability of the two parallel cores, $k_{\mathrm{H}} / k_{\mathrm{L}}$ ), and fluid flowback rates were analyzed.
The experimental results of three sets of parallel cores are shown in Table 5 and Figs. 15, 16 and 17. Compared the results of the two groups with similar permeabilities at the beginning of the experiment (e.g., the first and second groups of parallel cores), the ratio of permeability to brine before the chemical treatment (i.e., nanoemulsioncontaining working fluid) were 6.24 and 8.55 , while after treatment with chemical agents, the values decreased to 3.71 and 3.14, respectively. At the same time, due to the heterogeneity changes of the parallel cores, the flowback rates of $\mathrm{P}-1 / \mathrm{H}, \mathrm{P}-1 / \mathrm{L}, \mathrm{P}-2 / \mathrm{H}$, and $\mathrm{P}-2 / \mathrm{L}$ increased by $26.40 \%$, $74.97 \%, 22.77 \%$ and $63.26 \%$, respectively, compared with before treatment. In the chemical treatment stage, the nanoemulsion preferred to enter the relatively high-permeability cores, and then block the pores and throats in the relatively high-permeability core. This would change the permeability ratio of the parallel cores. After the follow-up brine injection was done, the gas fingering decreased and an even push to brine was formed when reverse gas displacement was conducted on the parallel cores. Therefore, the flowback rates of the relatively low-permeability cores $\mathrm{P}-1 / \mathrm{L}$ and $\mathrm{P}-2 / \mathrm{L}$ were improved more significantly compared with the relatively high-permeability cores $\mathrm{P}-1 / \mathrm{H}$ and $\mathrm{P}-2 / \mathrm{H}$. The initial permeability ratio of the first group of cores was lower than that 


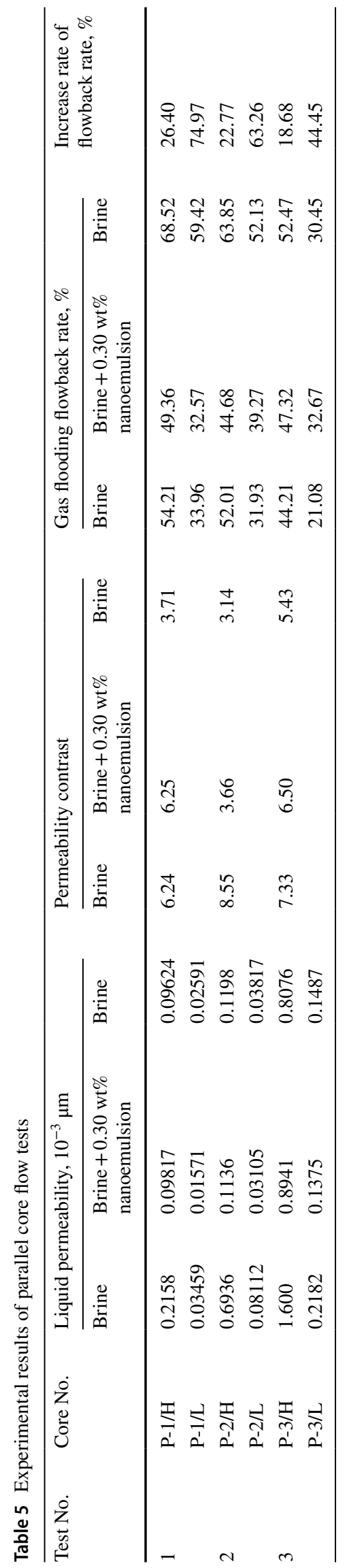

of the second group, thereby the gas flooding flowback rate increased greatly for the first group. Compared with the first group of cores, the initial permeability values of third group of cores were significantly higher, the increase rate of gas flooding flowback rate for $\mathrm{P}-3 / \mathrm{H}$ was $18.68 \%$, lower than that for $\mathrm{P}-1 / \mathrm{H}$, and the value for $\mathrm{P}-3 / \mathrm{L}$ was $44.45 \%$, lower than that for $\mathrm{P}-2 / \mathrm{L}$.

\section{Field applications}

The new nanoemulsion has been successfully used in the Sulige gas field in Changqing, which is a typical tight sandstone gas reservoir in western China. The nanoemulsion system has been applied to 31 wells. After the addition of the nanoemulsion to the fracturing fluid system, i.e., lowdamage fracturing fluid, the fluid flowback rate was significantly improved. When the amount of liquid nitrogen was reduced by $54.42 \%$, the flowback rate of the low-damage fracturing fluid was still increased by $14.27 \%$.

In 2019 , the average single-well daily gas production and open flow potential had steadily increased compared with 2018. In 2018, the average single-well daily output was $2.19 \times 10^{-4} \mathrm{~m}^{3}$ and the open flow potential was $7.39 \times 10^{-4} \mathrm{~m}^{3}$; while in 2019 , the output increased to $2.44 \times 10^{-4} \mathrm{~m}^{3}$ (increased by $16.9 \%$ ) and the absolute open flow rises to $7.99 \times 10^{-4} \mathrm{~m}^{3}$ (increased by $8.1 \%$ ) after using low-damage fracturing fluid.

\section{Conclusions}

This paper analyzes the differences in water blocking damage between the non-cracked and cracked cores. Pressure transmission tests were used to study the liquid flow capacity. The improvement effects of a new nanoemulsion on micro plugging and liquid flow capacity were evaluated based on parallel core flow tests. The main conclusions are as follows:

Water blocking damage caused by water saturation for non-cracked and cracked cores show large differences. The fractures in the cracked cores are the main channels for gas flow, while in the non-cracked cores are pores and throats. When the water blocking damage in the fracture was removed, the gas permeability of the cracked cores increased more significantly. Therefore, under the same water saturation, the gas permeability of the fractured cores suffered less damage than that for the non-cracked cores. Pressure 


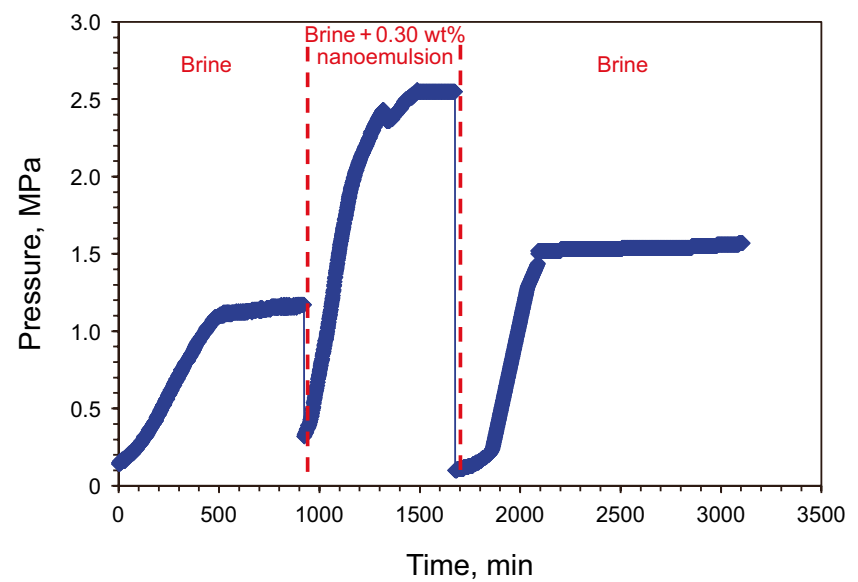

(a) Pressure versus time

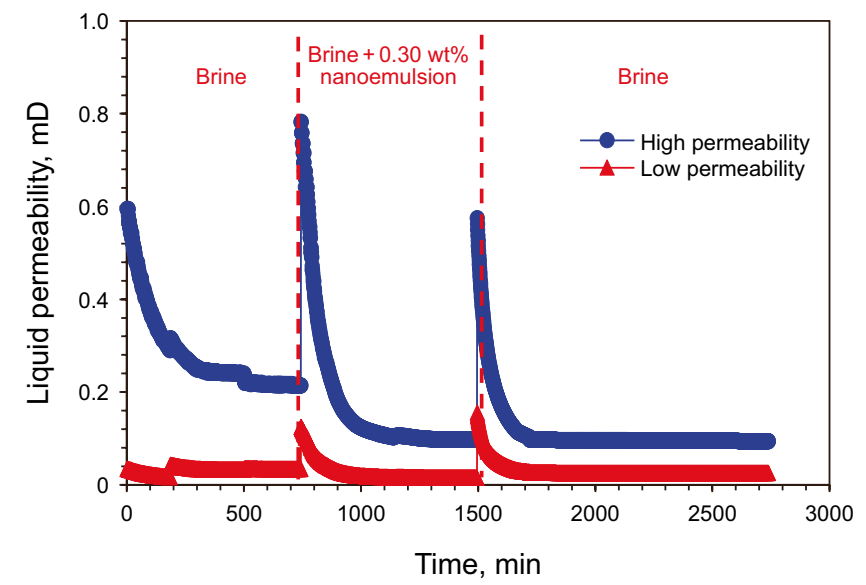

(b) Permeability versus

Fig. 15 Injection pressure and permeability curves for parallel cores $\mathrm{P}-1 / \mathrm{H}$ and $\mathrm{P}-1 / \mathrm{L}$

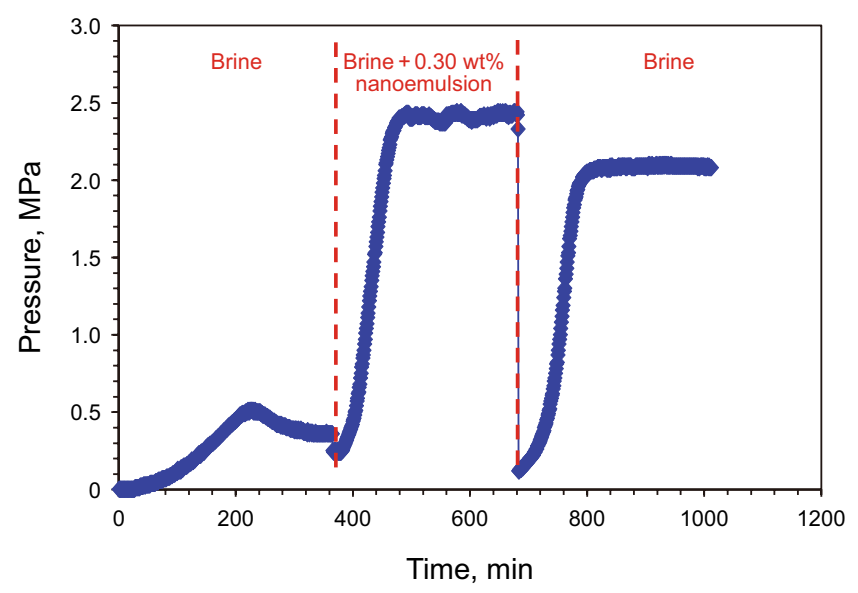

(a) Pressure versus time

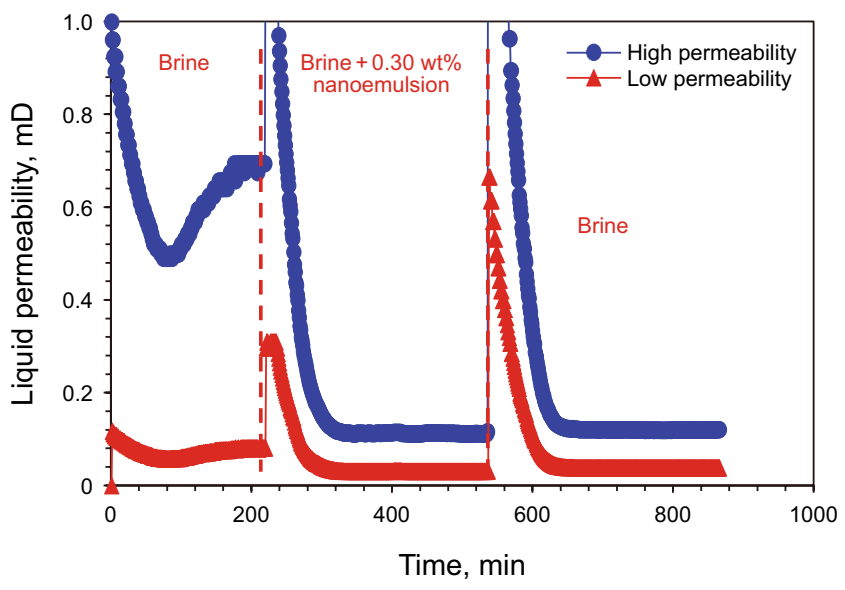

(b) Permeability versus

Fig. 16 Injection pressure and permeability curves for parallel cores $\mathrm{P}-2 / \mathrm{H}$ and $\mathrm{P}-2 / \mathrm{L}$

transmission tests show that the nanoemulsion can increase the liquid permeability in the non-cracked and cracked cores. Parallel core flow experiments show that, for tight sandstone gas reservoirs with a certain permeability ratio, nanoemulsion not only can alleviate reservoir heterogeneity but can also reduce the fingering degree of reverse gas flooding and increase the flowback rates of the fracturing fluid. The new nanoemulsion can be used as a fracturing fluid additive to increase the flowback rate and can reduce water blocking damage in tight sandstone gas reservoirs. 


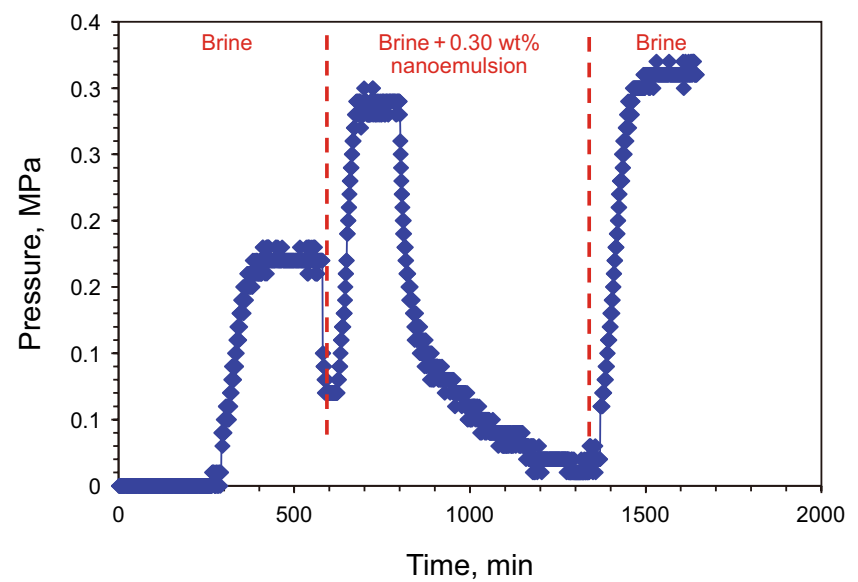

(a) Pressure versus time

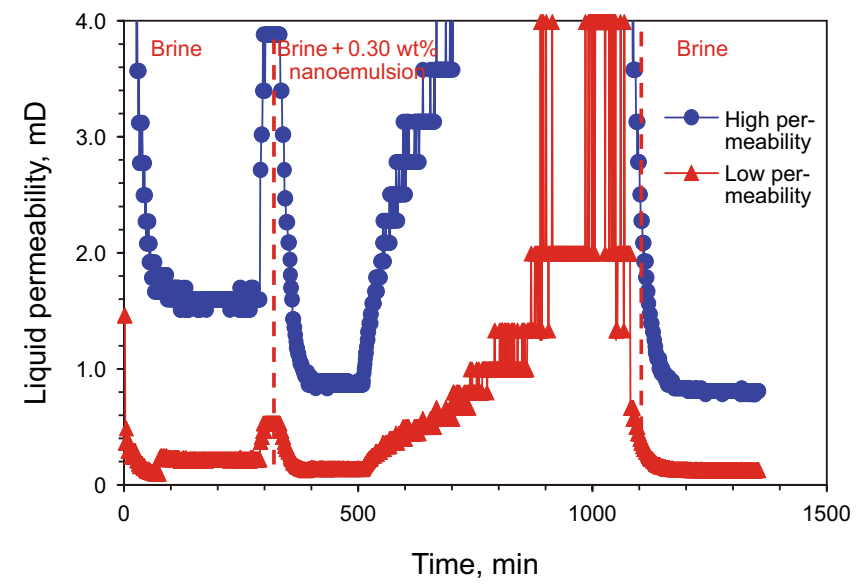

(b) Permeability versus

Fig. 17 Injection pressure and permeability curves for parallel cores $\mathrm{P}-3 / \mathrm{H}$ and $\mathrm{P}-3 / \mathrm{L}$

Acknowledgements This work is financially supported by the National Science Foundation of China (Grant No. 51804033), China Postdoctoral Science and Foundation (Grant No. 2018M641254), the National Science and Technology Major Projects of China (Grant Nos. 2016ZX05051, 2016ZX05014-005, and 2017ZX05030).

\section{Compliance with ethical standards}

Conflict of interest The authors declare that they have no competing of interest.

Open Access This article is licensed under a Creative Commons Attribution 4.0 International License, which permits use, sharing, adaptation, distribution and reproduction in any medium or format, as long as you give appropriate credit to the original author(s) and the source, provide a link to the Creative Commons licence, and indicate if changes were made. The images or other third party material in this article are included in the article's Creative Commons licence, unless indicated otherwise in a credit line to the material. If material is not included in the article's Creative Commons licence and your intended use is not permitted by statutory regulation or exceeds the permitted use, you will need to obtain permission directly from the copyright holder. To view a copy of this licence, visit http://creativecommons.org/licenses/by/4.0/.

\section{References}

Aminnaji M, Fazeli H, Bahramian A, et al. Wettability alteration of reservoir rocks from liquid wetting to gas wetting using nano fluid. Transp Porous Med. 2015;109(01):1-16. https://doi.org/10.1007/ s11242-015-0509-6.

Bahrami H, Rezaee R, Clennell B. Water blocking damage in hydraulically fractured tight sand gas reservoirs: an example from Perth Basin, Western Australia. J Petrol Sci Eng. 2012;88:100-6. https ://doi.org/10.1016/j.petrol.2012.04.002.

Brace W, Walsh JB, Frangos WT. Permeability of granite under high pressure. J Geophys Res. 1968;73(6):2225-36. https://doi. org/10.1029/JB073i006p02225.
Bybee K. Mechanism for permeability reduction by small water saturation in tight gas sandstones. J Petrol Technol. 2007;59(11):105-7. https://doi.org/10.1016/S0168-1656(99)00226-6.

Dicker AI, Smits RM. A practical approach for determining permeability from laboratory pressure-pulse decay measurements. In: International meeting on petroleum engineering, 1-4 November, Tianjin, China; 1988. https://doi.org/10.2118/17578-MS.

Dutta R, Lee CH, Odumabo S, et al. Experimental investigation of fracturing-fluid migration caused by spontaneous imbibition in fractured low-permeability sands. In: SPE Americas unconventional resources conference, Pittsburgh, Pennsylvania, USA, 5-7 Jun, 2012. https://doi.org/10.2118/154939-PA.

Eastoe J, Robinson BH, Steytler DC. Influence of pressure and temperature on microemulsion stability. J Chem Soc, Faraday Trans. 1990;86(3):511-7. https://doi.org/10.1039/ft99086005 11.

Gahrooei HRE, Ghazanfari MH. Application of a water based nanofluid for wettability alteration of sandstone reservoir rocks to preferentially gas wetting condition. J Mol Liq. 2017;232:35160. https://doi.org/10.1016/j.molliq.2017.02.097.

Hsieh PA, Tracy JV, Neuzil CE, Bredehoeft JD, Silliman SE. A transient laboratory method for determining the hydraulic properties of 'tight 'rocks-I. Theory. Int J Rock Mech Min Sci Geomech Abstr. 1981;18(3):245-52. https://doi.org/10.1016/01489062(81)90979-7.

Lei M, Huang WA, Li N, Jia JH, Li JX, Wang YW, et al. The damage mechanism of oil-based drilling fluid for tight sandstone gas reservoir and its optimization. J Pet Sci Eng. 2017;158:616-25. https://doi.org/10.1016/j.petrol.2017.09.003.

Li K, Firoozabadi AA. Experimental study of wettability alteration to preferential gas-wetting in porous media and its effects. SPE Reserv Eval Eng. 2000;3(2):139-49. https://doi. org/10.2118/62515-PA.

Li W, Zhao X, Li Y, et al. Laboratory investigations on the effects of surfactants on rate of penetration in rotary diamond drilling. $\mathrm{J}$ Pet Sci Eng. 2015;134:114-22. https://doi.org/10.1016/j.petro 1.2015.07.027.

Li W, Liu JS, Zeng J, et al. A fully coupled multidomain and multiphysics model for evaluation of shale gas extraction. Fuel. 2020;278:118214. https://doi.org/10.1016/j.fuel.2020.118214.

Liang T, Li Q, Liang X, Yao E, Wang Y, Li Y, et al. Evaluation of liquid nanofluid as fracturing fluid additive on enhanced 
oil recovery from low-permeability reservoirs. J Pet Sci Eng. 2018;168:390-9. https://doi.org/10.1016/j.petrol.2018.04.073.

Lin W. Compressible fluid flow through rocks of variable permeability. Technical report. no. UCRL-52304. California University. 1977. https://doi.org/10.2172/7080925.

Liu X, Kang Y, Luo P, You L, Tang Y, Kong L. Wettability modification by fluoride and its application in aqueous phase trapping damage removal in tight sandstone reservoirs. J Pet Sci Eng. 2015;133:201-7. https://doi.org/10.1016/j.petrol.2015.06.013.

Karandish G, Rahimpour M, Sharifzadeh S, et al. Wettability alteration in gas-condensate carbonate reservoir using anionic fluorinated treatment. Chem Eng Res Des. 2015;93:554-64. https:// doi.org/10.1016/j.cherd.2014.05.019.

Khlaifat AL, Qutob H, Barakat N. Tight gas sands development is critical to future world energy resources. In: SPE Middle East unconventional gas conference and exhibition, Muscat, Oman, 31 Jan-2 Feb, 2011. https://doi.org/10.2118/142049-MS.

Meng M, Zamanipour Z, Miska S, Yu M, Ozbayoglu EM. Dynamic stress distribution around the wellbore influenced by surge/ swab pressure. J Pet Sci Eng. 2019;172:1077-91. https://doi. org/10.1016/j.petrol.2018.09.016.

Noh MH, Firoozabadi A. Wettability alteration in gas-condensate reservoirs to mitigate well deliverability loss by water blocking. SPE Reserv Eval Eng. 2008;11(04):676-85. https://doi. org/10.2118/98375-PA.

Shao C, Yang Z, Zhou G, Lu G. Pore network modeling of water block in low permeability reservoirs. Pet Sci. 2010;7(3):362-6. https://doi.org/10.1007/s12182-010-0078-9.
Sharifzadeh S, Hassanajili S, Rahimpour M. Wettability alteration of gas condensate reservoir rocks to gas wetness by sol-gel process using fluoroalkylsilane. J Appl Polym. 2013;128(6):4077-85. https://doi.org/10.1002/app.38632.

Wang J, Zhou F, Zhang L, et al. Study on reason analysis and removal solution on water locking damage in tight sandstone reservoirs. J Dispers Sci Technol. 2019a. https://doi.org/10.1080/01932 691.2019.1637754.

Wang J, Zhou F, Xue Y, et al. The adsorption properties of a novel ether nanofluid for gas wetting of tight sandstone reservoir. Pet Sci Technol. 2019b;37(12):1436-54. https://doi. org/10.1080/10916466.2019.1590402.

You Q, Wang H, Zhang Y, et al. Experimental study on spontaneous imbibition of recycled fracturing flow-back fluid to enhance oil recovery in low permeability sandstone reservoirs. J Pet Sci Eng. 2018;166:375-80. https://doi.org/10.1016/j.petro 1.2018.03.058.

Zhang L, Zhou F, Mou JY, et al. A new method to improve longterm fracture conductivity in acid fracturing under high closure stress. J Pet Sci Eng. 2018;171:760-70. https://doi. org/10.1016/j.petrol.2018.07.073.

Zhang L, Zhou F, Mou JY, et al. Large-scale true tri-axial fracturing experimental investigation on diversion behavior of fiber using 3D printing model of rockformation. J Pet Sci Eng. 2019;181:106171. https://doi.org/10.1016/j.petrol.2019.06.035. 